\title{
PENGARUH PREHEAT DAN VARIASI ARUS PENGELASAN MENGGUNAKAN ELEKTRODA LB 52 TERHADAP KOMPOSISI KIMIA SIFAT MEKANIK DAN STRUKTUR MIKRO PADA PENGELASAN BAJA MANGAN AUSTENITIK
}

\author{
Eko Nugroho', Untung Surya Dharma ${ }^{2}$, Yasir Thalabi ${ }^{3}$ \\ Jurusan Teknik Mesin, Fakultas Teknik, Universitas Muhammadiyah Metro ${ }^{1,2,3}$ \\ Jl. Ki Hajar Dewantara 15 A Metro, Lampung \\ Email: exonugros@yahoo.co.id ${ }^{1}$, untungsdh@yahoo.co.id², yasirtha9594@gmail.com ${ }^{3}$
}

\begin{abstract}
Abstrak
Sambungan las merupakan sambungan permanen yang bila akan dilepas harus merusak sambungan las itu sendiri. Faktor pengelasan seperti welding oprator sangat mempengaruhi hasil pengelasan maka perlu juga diketahui bahwa elektroda yang digunakan adalah jenis mild steel A5.1 E7016, baja yang akan dilas yaitu baja mngan austenitik dengan 0,925\% kadar Carbon dan 10\% kadar Mangan, arus yang digunakan DC dengan variasi 100 A, 110 A, dan 120 A. Dengan penambahan panas $1000^{\circ} \mathrm{C}$, menggunakan kampuh $\mathrm{V}$ dengan sudut $80^{\circ}$. Dalam pengujian struktur mikro terlihat pada pengelasan 100 A, 110 A, 120 A non preheat, tidak didapatkan fasa baru atau pencampuran elektroda dan base metal tidak sempurna. Sedangkan las preheat terlihat pada 120A terdapat fasa baru dekat daerah HAZ (Head Affected Zone). Dan nilai kekerasan pada daerah HAZ preheat yaitu 10,5 HRC pada las $100 \mathrm{~A}, 10 \mathrm{HRC}$ pada las 110 A, dan 9 HRC pada las 120 A. Sedangkan pada daerah lasan 37,6 HRC pada las 100 A, 51 HRC pada las $110 \mathrm{~A}$, dan $40 \mathrm{HRC}$ pada las $120 \mathrm{~A}$.
\end{abstract}

Kata kunci: Sambungan las, elektroda LB 52, preheat dan non preheat.

\section{PENDAHULUAN}

Pembangunan kontruksi dengan logam pada masa sekarang ini banyak melibatkan unsur pengelasan khususnya bidang kontruksi mesin yang dibuat menjadi lebih ringan, serta pembuatannya mudah dilakukan dan lebih ekonomis [1].

Baja mangan austenitik merupakan salah satu baja paduan yang mengandung 0,9-1,2 \% karbon dan 11-14 \% mangan. Tingginya kadar karbon dan mangan membuat material ini pada temperatur $1050^{\circ} \mathrm{c}$ mengandung fasa austenite yang sangat dominan [2]. Baja ini memiliki ketahanan terhadap keausan, kekerasan yang cukup tinggi, ketangguhan yang baik dan tahan terhadap korosi, sehingga aplikasinya banyak dimanfaatkan untuk peralatan-peralatan yang mengalami beban yang besar dan keausan tinggi seperti stone crusher, hammer mill, dan rail crusher [3]. Proses pembentukan baja mangan adalah dengan pengecoran sehingga kemungkinan cacat pada produk bisa saja terjadi [4]. Baja mangan juga jarang dilakukan pengelasan dengan menggunakan jenis elektroda mild stell karena komposisi yang berbeda, di sisi lain, sifat fisik kedua bahan ini menciptakan masalah dalam proses pengelasan karena sifat fisik dan pengelasan yang berbeda. Dua konsekuensi ini dapat menyebabkan masalah retak dingin di zona yang terkena dampak panas. Jika kita menerapkan proses pemanasan awal dengan kecepatan pendinginan yang terkontrol untuk bagian austenitik dari sambungan las, kita dapat memperbaiki kemampuan las baja [5].

$$
\text { Pemanasan awal dapat }
$$

didefinisikan sebagai pemanasan logam dasar sampai suhu tertentu sebelum pengelasan [6]. Dalam dunia pengelasan pemanasan ini digunakan untuk menambahkan panas pada logam induk apabila logam yang disambung dan elektroda yang dipakai berbeda spesifikasi maupun sifatnya dan perbedaan material ini 
tentu akan mempengaruhi logam induk atau daerah HAZ (Head Affected Zone) [7].

Penelitian ini bertujuan untuk mengetahui apakah sambungan tak sejenis yaitu elektroda LB 52 dengan baja mangan austenitik yang memiliki sifat mekanik dan komposisi kimia berbeda dapat menyatu dengan baik.

\section{METODE PENELITIAN}

Pada penelitian ini digunakan elektroda dengan kode AWS A5.1 E7016 dengan diameter elektroda $3.2 \mathrm{~mm}$ dengan fluks terbungkus juga digunakan untuk melindungi kontak langsung dengan oksigen yang akan mempengaruhi hasil pengelasan.

Mesin las yang digunakan adalah Arcehwel the sanghai elektronik.co.ltd. Ampere yang digunakan 100 A, 110 A, 120 A. Jenis arus DC, dengan penambahan panas awal $1000^{\circ} \mathrm{C}$ dan tanpa pemanasan. Jenis pengelasan pada penelitian ini SMAW (shielded metal arc welding) dengan kecepatan pengelasan $2 \mathrm{~mm} / \mathrm{s}$.

Baja yang digunakan untuk penelitian ini adalah baja mangan plat ukuran 300 x $300 \mathrm{~mm}$ dan tebal $8 \mathrm{~mm}$ hasil pengecoran BPTM LIPI Lampung dengan kandungan $\mathrm{Mn} 9,82 \%$, yang kemudian dipotong dengan ukuran 300 x $30 \mathrm{~mm}$, kedua sisi pada kedua baja tersebut dibuat kampuh V $80^{\circ}$.

Setelah selesai dilakukan pengelasan kemudian dilakukan uji optical emision spectrocopy (OES) untuk mengetahui komposisi pada daerah base metal dan daerah weld metal apakan pada daerah las terjadi perubahan komposisi kimia setelah dilakukan pengelasan. Dengan proses yaitu mengamplas, memoles dengan coolant larutan $\mathrm{TiO}_{2}$ dan aquades dengan perbandingan $10 \mathrm{~g}$ bubuk $\mathrm{TiO}_{2}$ dilarutkan dengan $20 \mathrm{ml}$ aquades. Etsa dilakukan dengan larutan nital $2 \%$ selama 2-5 detik, pemeriksaan struktur mikro dengan mikroskop optik dan dilakukan pemotretan pada daerah base jauh HAZ, base dekat HAZ, daerah HAZ, dan pada daerah weld dekat HAZ, weld jauh HAZ.
Dengan pembesaran $100 \mathrm{x}$ dari foto mikro struktur dapat dilihat fasa yang terbentuk dan bagian-bagian base metal yang cair masuk ke dalam daerah weld, dan pengaruh sifat mekanik.

Pengujian selanjutnya pengujian yang dilakukan dengan menggunakn standar ASME pada uji metalografi, uji kekerasan, dan uji impak. Pengujian metalografi bertujuan untuk mengetahui fasa apa saja yang terjadi dari sambungan antara logam las dan logam induk setiap variasi las yang dilakukan dan efek pemanasan awal yang diberikan pada logam induk.

Uji kekerasan dilakukan untuk mengetahui berapa kekerasan pada base metal dan pada daerah HAZ, dan Weld Metal setelah terjadi pemanasan akibat penambahan panas awal dan akibat busur las itu sendiri. Pengujian ini dilakukan dengan alat Hardness Tester dengan masing-masing diambil tiga titik pengujian, dengan skala $\mathrm{C}$.

\section{HASIL DAN PEMBAHASAN}

Setelah dilakukan persiapan sampel masing-masing pengujian, diperoleh data sebagai berikut.

Tabel 1. Komposisi Kimia Elektroda AWS A5.1 E7016

\begin{tabular}{|c|c|c|}
\hline Carbon \% & Mn \% & Si \% \\
\hline 0,08 & 0,94 & 0,60 \\
\hline
\end{tabular}

Tabel 2. Komposisi kimia Baja Mangan

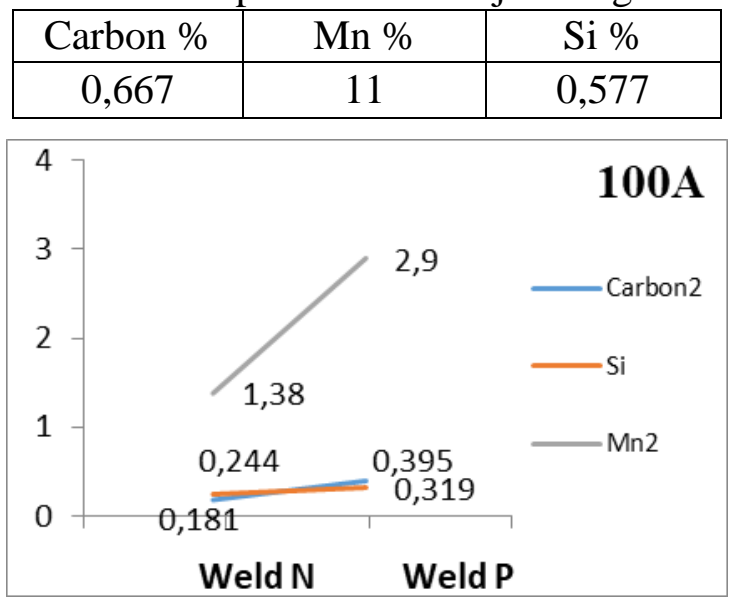

Gambar 1. Komposisi kimia hasil pengelasan 100 A non preheat-preheat 


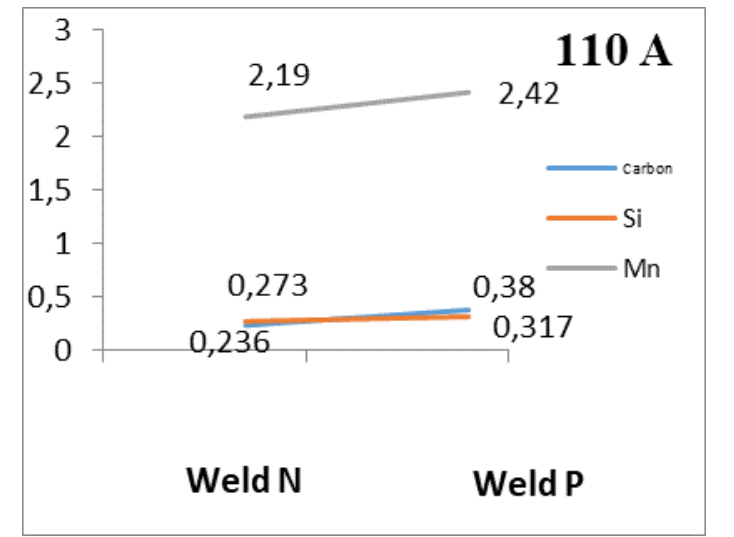

Gambar 2. Komposisi kimia hasil pengelasan 110 A non preheat-preheat

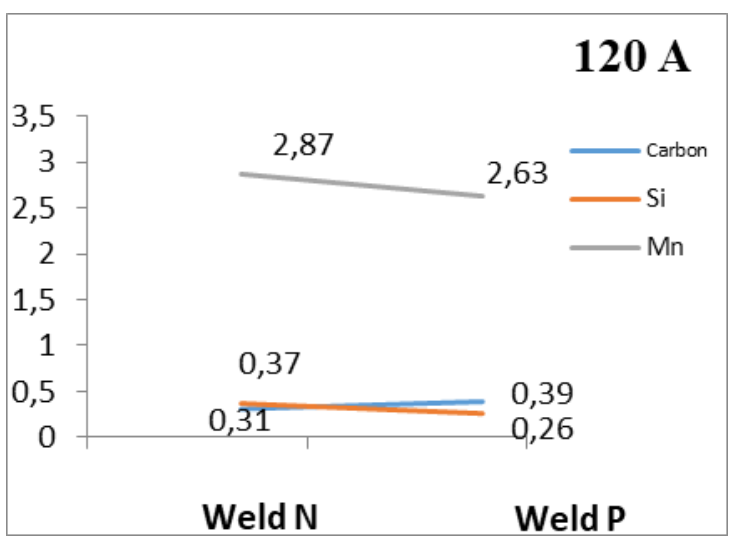

Gambar 3. Komposisi kimia hasil pengelasan 120 A non preheat-preheat

Pada tabel dan grafik di atas menunjukan bahwa mangan memang sudah mencair pada pengelasan 100 A non preheat, namun belum terlalu besar dibandingkan dengan 100 A dengan preheat ini menunjukan adanya perlakuan preheat membuat base metal lebih mudah mencair dan menyatu dengan logam las. Meningkatnya jumlah mangan semakin bertambah pada pengelasan 110 A baik tanpa preheat ataupun dengan preheat pada metode preheat meningkatnya jumlah mangan cukup tinggi justru pada pengelasan $100 \mathrm{~A}$ dan yang paling rendah pada 110 A sedangkan pengelasan non preheat meningkatnya jumlah mangan tergantung pada arus yang digunakan seperti terlihat pada gambar 2. Ini menunjukkan pengaruh panas yang dihasilkan oleh pengelasan akan berpengaruh dengan logam induk untuk mencair.

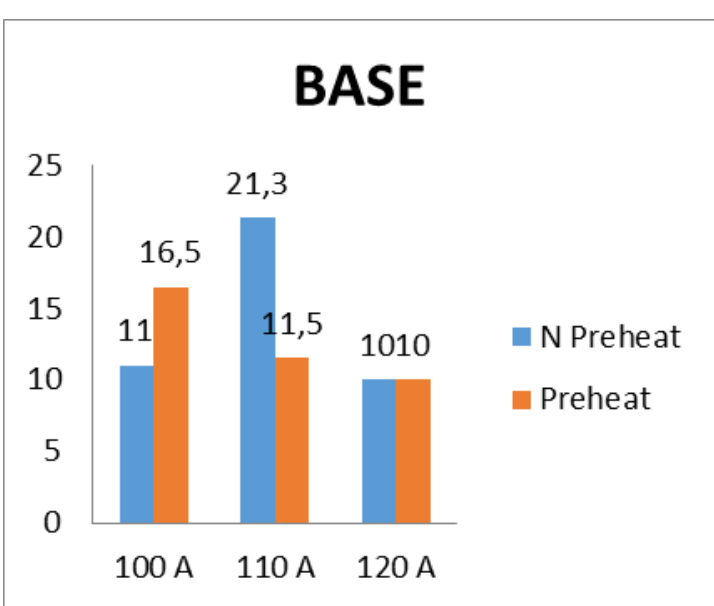

Gambar 4. Pengujian kekerasan rockwell dengan skala HRC pada daerah base metal

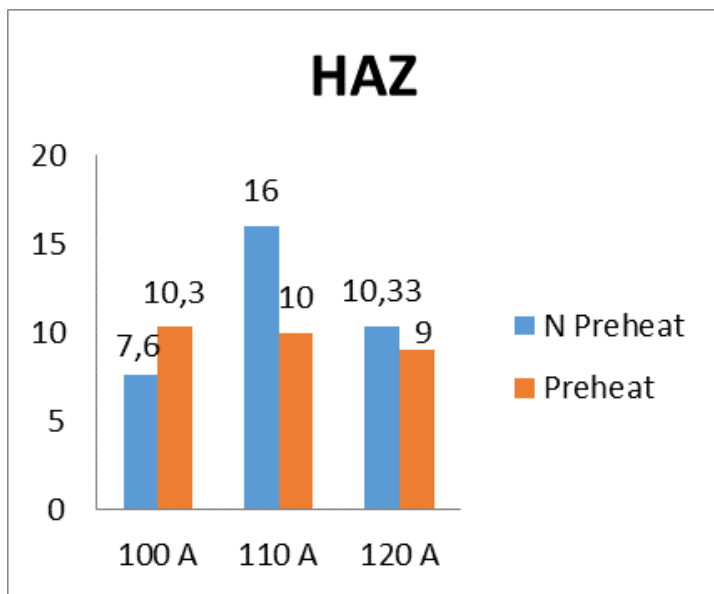

Gambar 5. Pengujian kekerasan rockwell dengan skala HRC pada daerah HAZ

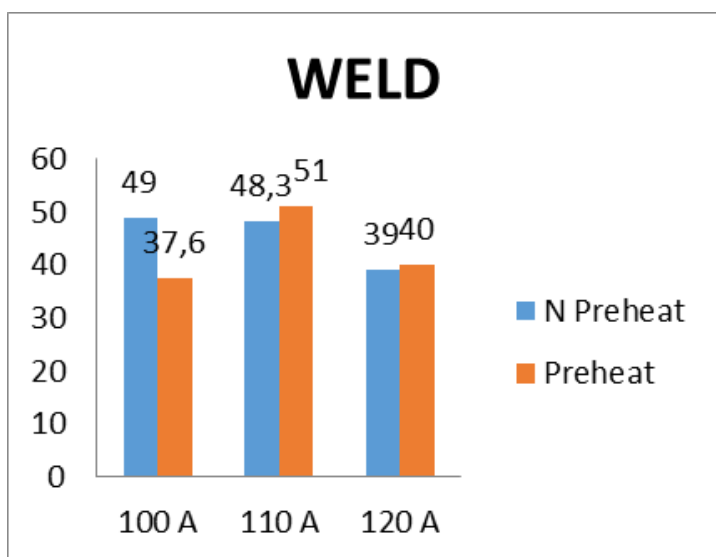

Gambar 6. Pengujian kekerasan rockwell dengan skala HRC pada daerah weld metal

Pengaruh panas dan komposisi kimia memang sangat mempengaruhi sifat mekanik seperti kekerasan [9], jika dilakukah heat treatment sampai suhu austenit dan didinginkan secara cepat maka akan menjebak bainit yang akan mengakibatkan kekerasan akan meningkat, 
namun sebaliknya jika pendinginan dilakukan secara perlahan yang akan menyebabkan baja menjadi lunak [5]. Seperti pada grafik di atas pengujian dilakukan dengan metode Rockwell Hardness brinell HRC. Pada base metal baik yang dilakukan preheat dan non preheat memang tidak ada perbedaan. Kekerasan pada base metal cukup tinggi pada 100 A preheat dan 110 A non preheat. Kemudian pada daerah HAZ semakin besar arus yang digunakan kekerasan pada masing-masing sampel menurun ini dikarenakan pendinginan cukup lambat untuk memghindari cracking pada bagian interface karena pendinginan cepat. Dan daerah weld metal memang berbeda komposisi kimia, ini yang menyebabkan perbedaan kekerasan pada daerah weld metal sangat tinggi dibandingkan dengan base metal dan HAZ.

Tabel 3. Hasil pengujian impak metode charpy

\begin{tabular}{|c|c|c|}
\hline $\begin{array}{c}\text { Jenis } \\
\text { Perlakuan }\end{array}$ & $\begin{array}{l}\text { No } \\
\text { Tes }\end{array}$ & $\begin{array}{c}\text { Energi Impak } \\
\text { (Joule) }\end{array}$ \\
\hline \multirow{2}{*}{$\begin{array}{c}100 \mathrm{~A} \\
\text { non preheat }\end{array}$} & 1 & 9 \\
\hline & 2 & 5 \\
\hline \multirow{2}{*}{$\begin{array}{l}110 \mathrm{~A} \\
\text { preheat }\end{array}$} & 1 & 4 \\
\hline & 2 & 4 \\
\hline \multirow{2}{*}{$\begin{array}{c}110 \mathrm{~A} \\
\text { non preheat }\end{array}$} & 1 & 14 \\
\hline & 2 & 5 \\
\hline \multirow{2}{*}{$\begin{array}{c}110 \mathrm{~A} \\
\text { preheat }\end{array}$} & 1 & 4 \\
\hline & 2 & 4 \\
\hline \multirow{2}{*}{$\begin{array}{c}120 \mathrm{~A} \\
\text { non preheat }\end{array}$} & 1 & 3 \\
\hline & 2 & 6 \\
\hline \multirow{2}{*}{$\begin{array}{l}120 \mathrm{~A} \\
\text { preheat }\end{array}$} & 1 & 5 \\
\hline & 2 & 4 \\
\hline
\end{tabular}

Pada pengujian impak dapat disimpulkan bahwa kekuatan pengelasan memang cukup getas hanya mampu menahan beban impak rata-rata di bawah 10 Joule ini disebabkan karena pencampuran persentase komposisi kimia dari logam induk dan logam las. Perilaku patahan ditemukan bergantung pada ukuran butir. Semakin besar ukuran butir maka kekuatan dari suatu material semakin menurun disebabkan karena lebih sedikit batas butir yang menyebabkan adanya konsentrasi tegangan [8], adanya cacat besar dan kecil, dan peningkatan masukan panas juga mempengaruhi proporsi unsur penyusun struktur mikro yang berbeda dari logam las dan HAZ. Ditemukan bahwa ketika tingkat pendinginan menurun, kualitas kristal meningkat dan kekerasan mikro juga meningkat.

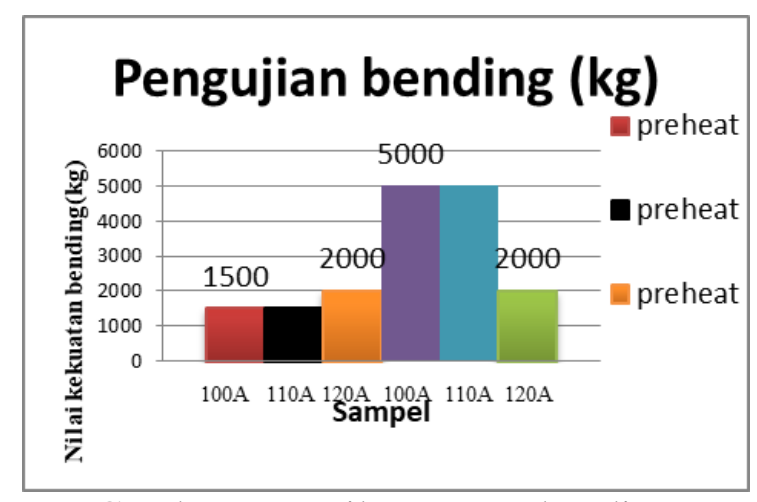

Gambar 7. Hasil tegangan bending maksimum pada masing-masing variasi

$(\mathrm{kg})$

Pada pengujian bending ada beberapa perbedaan dari perlakuan panas yang dilakukan harga kekuatan bending perlakuan panas atau preheat pada sampel 100 A dan 110 A preheat memiliki harga yang sama yaitu $1500 \mathrm{~kg}$, paling rendah dibandingkan dengan sampel-sampel non preheat atau tanpa perlakuan panas, pada sampel 120 A preheat harga kekuatan bending meningkat sebesar $2000 \mathrm{~kg}$. Pada pengelasan tanpa preheat harga kekuatan bending justru cukup tinggi yaitu pada sampel 100 A dan 110 A non preheat sebesar $5000 \mathrm{~kg}$, namun terdapat penurunan pada sampel 120 A non preheat sebesar $2000 \mathrm{~kg}$ ini karena dalam proses pemasukan panas pada sampel $100 \mathrm{~A}$ dan 110 A nonpreheat tidak terlalu tinggi dari sampel yang lain dan dengan pendinginan yang lambat juga akan mengurangi sifat mekanik baja. 


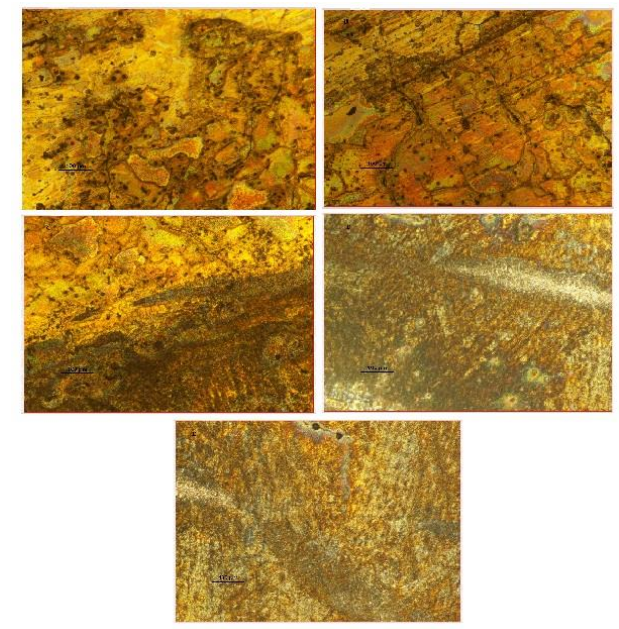

Gambar 8. Struktur mikro pengelasan 100 A non preheat (perbesaran $100 \mathrm{X}$ )


Gambar 9. Struktur mikro pengelasan 100 A preheat (perbesaran $100 \mathrm{X}$ )

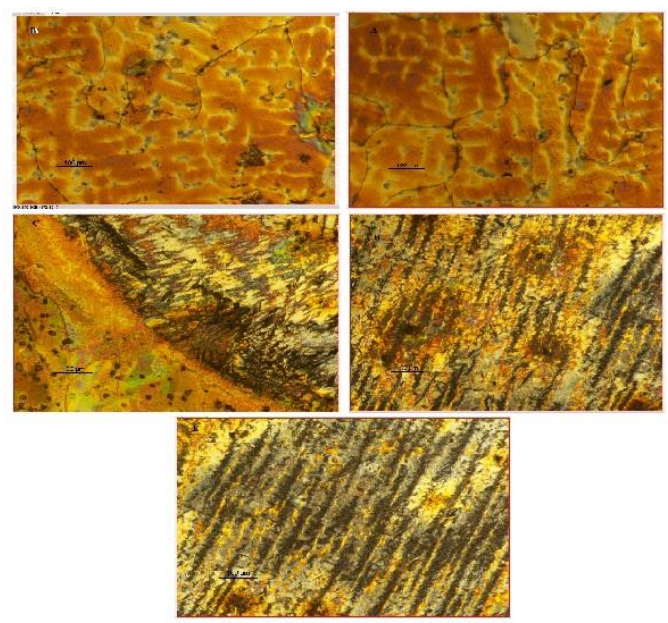

Gambar 10. Struktur mikro pengelasan 110 A non preheat (perbesaran $100 \mathrm{X}$ )



Gambar 11. Struktur Mikro pengelasan 110 A Preheat (perbesaran $100 \mathrm{X}$ )

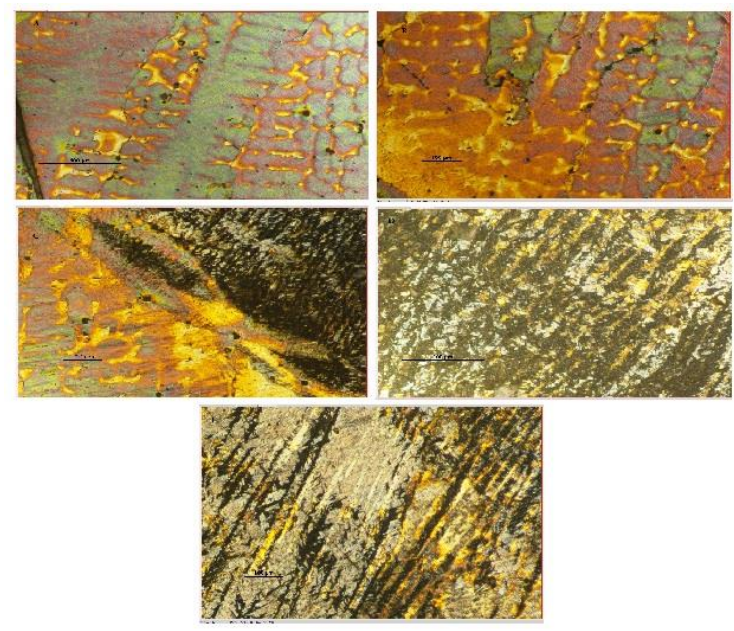

Gambar 12. Struktur mikro pengelasan 120 A non preheat (perbesaran $100 \mathrm{X}$ )

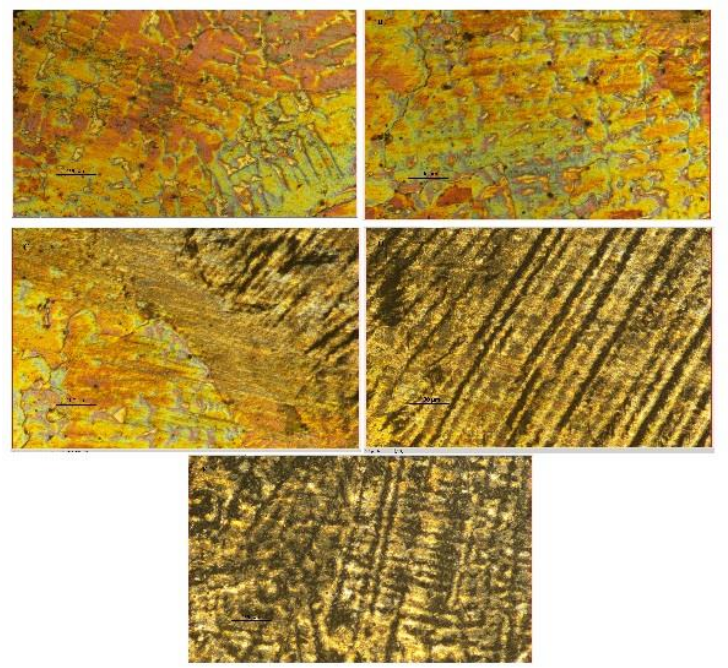

Gambar 13. Struktur mikrro pengelasan 120 A preheat (perbesaran $100 \mathrm{X}$ )

Pada gambar struktur mikro pada daerah interface disini akan terlihat 
pencairan logam induk dan logam las akan menghasilkan struktur mikro yang akan mempengaruhi kekuatan mekanik pada hasil pengelasan [10]. Pada Gambar 8 pembentukan fasa ini hampir tidak ada atau logam induknya tidak mengalami tranformasi ke dalam logam las seperti pada gambar 13 yang dimana pada daerah interface terdapat fasa baru di antara logam induk dan logam las. Pada gambar 10 struktur mikro pada daerah interface terlihat logam induk mengikat atau memanjang ke arah lasan, dan pada gambar 12 , logam induk dapat masuk dan berikatan dengan logam las namun tidak membentuk fasa baru. Gambar 9 juga terjadi penggumpalan pada struktur mikro tetapi logam induk dapat bertransformasi ke dalam logam las sehingga terlihat pada gambar di atas yang menunjukan lelehan logam induk namun tidak membentuk fasa baru seperti pada Gambar 13. Gambar 11 juga menunjukkan hal yang sama dengan Gambar 9, dimana fasa belum terbentuk sempurna kejadian seperti ini tidak akan menguntungkan untuk pengelasan berbeda komposisi dan sifat mekanik.

\section{KESIMPULAN}

Berdasarkan hasil penelitian yang dilakukan dapat disimpulkan bahwa:

1. Komposisi kimia pada daerah las yang terpengaruh oleh logam induk akan sangat berpengaruh terhadap sifat fisik hasil pengelasan. Naiknya komposisi Mangan dan Carbon pada daerah las dan turunnya komposisi Silikon juga sangat berpengaruh terhadap sifat fisik dan mekanik baja,

2. Pengelasan dengan memnggunakan preheat serta dengan pendinginan yang lambat akan mempengaruhi kekerasan pada daerah HAZ menurun meski tidak terlalu signifikan, dan kekerasan pada daerah las tinggi hal ini akan mempengaruhi salah satu sifat mekanik baja,

3. Kekuatan impak pada masing-masing spesimen rendah hanya di bawah 10 Joule saja ini cukup beralasan jika dilihat dari jenis patahan yang dimiliki setiap sampel,

4. Pada struktur mikro pencampuran komposisi logam induk dan logam las terjadi dengan baik. Sehingga terbentuk fasa baru di daerah las dekat dengan daerah HAZ.

\section{REFERENSI}

[1]. Djoko Supriyanto 2013. Pengaruh bentuk kampuh terhadap kekuatan bending las sudut smaw posisi mendatar pada baja karbon rendah. Seminar nasional ke 8- tahun 2013; Rekayasa Teknologi Industri Dan Informasi.

[2]. J. Mendez, M. Ghoreshy, W.B.F. Mackay, T.J.N. Smith, R.W. Smith" 2004 Weldability Of Austenitik Manganese steel Journal of Material Processing Tecnologi 153154(2004) 596-602.

[3]. Boby Endi Kurniawan, Yuli Setiyorini 2014. Pengaruh Variasi Holding Time Pada Perlakuan Panas Quench Annealing Tehadap Sifat Mekanik Dan Mikro Struktur Pada Baja Mangan AISI 3401. JURNAL TEKNIK POMITS Vol. 3, No. 1, (2014) ISSN: 2337-3539 (2301-9271 Print).

[4]. A Yudia Bakti, A Wahid, Rommy Cristian 1998. Pengaruh Parameter Las Terhadap Perubahan Struktur Mikro Dan Kekerasan Dari Baja Mangan Austenitik Hasil Cor (As-Cast). METAL INDONESIA VOL 020/98.

[5]. Eva Schmidova, Ivo Hlvaty, Petr Hanus 2016 The Weldability Of The Steel With High Manganese. Tehnicki vjesninik 23, 3(2016), 749-752.

[6]. Heshmat A. Aglan, Sudan Ahmed, 
Kaushal R. Prayakarao, Mahmood Fateh. 2013 . Effect Of Preheating Temperature On The Mechanical And Fracture Properties Of Welded Pearlitic Rail Steels. Engineering, 2013, 5, 837-843 Published Online November 2013 (http://www.scirp.org/journal/e ng)

http://dx.doi.org/10.4236/eng.2 013.511101

[7]. Asibeluo I.S, Emifoniye E. September 2015. Effect Of Arc Welding Current On The Mechanical Properties Of A36 Carbon Steel Weld Joints. SSRG International Journal of Mechanical Engineering (SSRG-IJME) - volume 2 Issue 9. ISSN 2348-8360

[8]. E. Curiel- Reyna, I. Rojas-Rodriguez, J. Terán, A. Del Real, A. LaraGuevara, and M. E. RodríguezGarcia 2014. Postcooling Treatment Impact On Mechanical Properties Of Welded Hadfield Steel Pieces. Journal of Emerging Trends in Engineering and Applied Sciences (JETEAS) 5(2): 105110 c Scholarlink Research Institute Journals, 2014 (ISSN: 2141-7016) jeteas.scholarlinkresearch.org, jeteas.scholarlinkresearch.com

[9]. K.M.Kenchireddy, C.T.Jayadeva and Sreenivasan.A 2014. Some Studies Of Hardfacing And Metallurgical Properties of Mild Steel Using Shielded Metal Arc Welding Processes. Global journal of engineering science and researches ISSN 23488038 .

[10]. M. EVANS 1980 Effect Of Manganese on The Microstrkture And Properties
Of All-Weld-Metal Deposits.

SUPPLEMENT TO THE

WELDING JOURNAL,

MARCH 1980.

[11]. ASME 2001 sec 09. Cualification Standard For Welding And Brazing Procedures, Welders, BRAZERS,AND WELDING AND BRAZING OPERATORS.

[12]. AWS A5.1 91 2003. Specification For Carbon Steel Elektrodes For Shielded Metal Arc Welding. 